\title{
Temperature-Programmed Reduction of Copper-Manganese Catalysts Derived from Biomass Activated Carbon
}

\author{
Arfaezah Anuar ${ }^{1}$, Ibrahim Yakub ${ }^{2}$, Norsuzailina Mohamed Sutan ${ }^{3}$, Cirilo Nolasco Hipolito ${ }^{4}$, \\ and Yun Hin Taufiq-Yap ${ }^{5}$ \\ ${ }^{1}$ Department of Chemical Engineering and Energy Sustainability, Universiti Malaysia \\ Sarawak, Kuching, Sarawak.Email: arfaezah_anuar@yahoo.co.uk \\ ${ }^{2}$ Department of Chemical Engineering and Energy Sustainability, Universiti Malaysia \\ Sarawak, Kuching, Sarawak. Email: yibrahim@feng.unimas.my \\ ${ }^{3}$ Department of Civil Engineering, Universiti Malaysia Sarawak, Kuching, Sarawak. \\ Email: msnorsuzailina@feng.unimas.my \\ ${ }^{4}$ Department of Molecular Biology, Universiti Malaysia Sarawak, Kuching, Sarawak. \\ Email: hcnolasco@frst.unimas.my \\ ${ }^{5}$ Department of Chemistry, Universiti Putra Malaysia, Serdang, Selangor. \\ Email:taufiq@upm.edu.my
}

\begin{abstract}
This study investigates the potential of bimetal impregnated catalysts supported on activated carbon derived from biomass for Selective Catalytic Reduction (SCR) of Nitrogen Oxides $\left(N O_{x}\right)$ with ammonia $\left(\mathrm{NH}_{3}\right)$. The bimetal catalysts, Copper-Manganese $(\mathrm{Cu}-\mathrm{Mn})$ was deposited onto palm kernel shell $(P K S)$ and coconut shell (CS) via impregnation method and calcined at $250{ }^{\circ} \mathrm{C}$. Hydrogen Temperature-programmed reduction analysis $\left(\mathrm{H}_{2}-\mathrm{TPR}\right)$ using 5\% Hydrogen gas $\left(\mathrm{H}_{2}\right)$ in Argon $(\mathrm{Ar})$ have been carried out to study the effect of different variables such as metal impregnation and support properties on the reduced states of the catalysts. Besides, FTIR, TGA and XRD were also used to characterize the catalysts. It was observed that impregnation of bimetals enhanced the catalyst characteristics where include important results from FTIR, TGA, XRD and $\mathrm{H}_{2}-T P R$. Based on the results presented in $H_{2}$-TPR analysis, it was observed that the reduction peak of bimetal catalysts deposited on palm kernel shell activated carbon shifted to high temperature, about $597{ }^{\circ} \mathrm{C}$. This demonstrates the intensity of the precursor interaction exists and a higher dispersion of bimetals on the surface of the support. In addition, the higher dispersion of bimetals was shown in XRD analysis. Hence, palm kernel shell-derived catalysts could be new and promising catalysts in SCR system.
\end{abstract}

Keywords: Activated carbon, Catalyst, SCR, $H_{2}-T P R, X R D$

\section{Introduction}

Nitrogen oxides $\left(\mathrm{NO}_{\mathrm{x}}\right)$ are one of the greenhouse gases with an atmospheric lifespan of 1 to 7 days for nitric oxide and 170 years for nitrogen dioxide [1]. The origins of $\mathrm{NO}_{\mathrm{x}}$ are categorized into mobile and stationary sources where, mobile source refers to combustion of fossil fuels from automobile system; meanwhile stationary source is referring to emission of flue gas due to combustion of coke from electrical power plants. Emission of $\mathrm{NO}_{\mathrm{x}}$ to the atmosphere has been linked to a variety of environmental problems including rain acidification, global warming, photochemical smog, formation of ground level ozone and greenhouse effects, as well as health related issues such as

Manuscript History:

Received 11 August, 2014, Revised 25 September, 2014, Accepted 26 September, 2014, Published 30 September, 2014

e-ISSN 2289-7771

Copyright $(2014$ JASPE

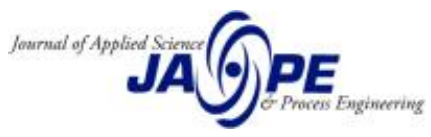


bronchitis and pneumonia [2]-[3]. Thus, various methods have been studied in recent years to reduce the amount of $\mathrm{NO}_{\mathrm{x}}$ emitted to the atmosphere in which one of those is catalytic technology [3].

Selective Catalytic Reduction (SCR) of $\mathrm{NO}_{\mathrm{x}}$ to $\mathrm{N}_{2}$ is one of the most effective and widespread treatment for the abatement of the emission of this pollutant to the atmosphere. Nowadays, $\mathrm{NH}_{3}-\mathrm{SCR}$ technology is advantageous for stationary sources such as thermal power plant and refinery plant at temperature of more than $300{ }^{\circ} \mathrm{C}$ using metal oxides such as manganese, molybdenum, and copper supported on titanium dioxide as the catalysts [4]. Besides, $\mathrm{TiO}_{2}-\mathrm{V}_{2} \mathrm{O}_{5}$ catalyst exerts high efficiency in the temperature range of $300{ }^{\circ} \mathrm{C}$ to $400{ }^{\circ} \mathrm{C}$ [5]-[6]. However, at this temperature window, the flue gases have high concentrations of contaminants, for example, $\mathrm{SO}_{2}$ and particulate matter that may cause deactivation and poisoning of the catalyst [5]. Other transition metals have been reported as active for SCR process at temperature of more than $300{ }^{\circ} \mathrm{C}$. The main problems in these catalysts are that still exhibit low-catalytic activities and poor resistance to catalyst poisoning [7]. Hence, there is a big interest to develop SCR catalyst which are active at lower temperatures, than $300{ }^{\circ} \mathrm{C}$, where only small amount of particulates and $\mathrm{SO}_{2}$ can be found in the flue gases, therefore, the deactivation and poisoning of the catalyst can be prevented [5].

Activated carbon (AC) is known for its extraordinarily large internal surface area and pore volume, which give activated carbon large adsorbent capacity. They have large surface area, up to $3000 \mathrm{~m}^{2} / \mathrm{g}$ with pore volume range from 0.20 to $0.60 \mathrm{~cm}^{3} / \mathrm{g}$ [8]-[9]. The surface area of activated carbon is formed by a micro-porous structure with pore diameters smaller than $2 \mathrm{~nm}$ [9]. Surface modification of $\mathrm{AC}$ can be done using bimetallic impregnation as it helps to enhance the catalyst properties to capture $\mathrm{NO}_{\mathrm{x}}$. Several raw materials for example cotton stalks, bituminous coals, palm kernel shell and coconut shell have been proposed to produce AC, where several studies have been done and the results indicate that the activated carbon has the potential to act as a catalytic support material. In addition, in Malaysia the wastes from palm shell and coconut shell are abundantly available and these wastes may pollute the environment. Thus, utilization of the agricultural wastes in developing countries, in Malaysia, is essential to promote greener environment and to sustain the natural resources. Apart being economically feasible, AC exhibits high catalytic activity at temperature between $100{ }^{\circ} \mathrm{C}-250{ }^{\circ} \mathrm{C}$, which fulfilled the requirements of SCR catalysts [10]. Considering the state of the art described above, the aim of this paper is to investigate the ability of carbon-supported $\mathrm{Cu}-\mathrm{Mn}$ catalyst for $\mathrm{NO}_{\mathrm{x}}$ reduction with $\mathrm{NH}_{3}$.

\section{Experimental}

\subsection{Catalyst Preparation}

The granular activated carbon (AC), derived from coconut shell (CS) and palm kernel shell (PKS) was purchased from a local supplier. It was left to dry in the laboratory-scale oven at $100{ }^{\circ} \mathrm{C}$, overnight. Each AC was impregnated with manganese and copper salts with a ratio of 1:1 and $10 \mathrm{wt} \%$ total metals loading. After gentle agitation at room temperature for 1 hour, the sample was left in a cabinet for one day [12]. After that, the impregnated AC was washed with distilled water until the effluents attained $\mathrm{pH}$ 6-7, to ensure that the residual impregnation solution is removed [11]. The resulting catalysts were allowed to dry overnight in the oven [12].

For calcination process, the catalysts were heated in a controlled environment for 4 hours at 250 ${ }^{\circ} \mathrm{C}$. The samples were then placed in sample bags and kept in vacuumed desiccator. Catalyst developed using CS and PKS are denoted as $\mathrm{Cu}-\mathrm{Mn} / \mathrm{CS}$ and $\mathrm{Cu}-\mathrm{Mn} / \mathrm{PKS}$ respectively. 


\subsection{Catalyst Characterization}

Both activated carbon (CS and PKS) and their derivatives $(\mathrm{Cu}-\mathrm{Mn} / \mathrm{CS}$ and $\mathrm{Cu}-\mathrm{Mn} / \mathrm{PKS})$ were characterized using Fourier-Transform Infrared Spectroscopy (FTIR), Thermo-gravimetric Analysis (TGA) and X-ray Diffraction (XRD).

FTIR analysis was carried out using Thermo Nicolet 380 (Thermo Scientific, USA) where the samples were mixed with $\mathrm{KBr}$, and the spectra were recorded within the range of $400 \mathrm{~cm}^{-1}$ to $4000 \mathrm{~cm}^{-}$

${ }^{1}$ to identify the oxygen functional groups on the catalysts surface [10].

Besides, TGA curves of the samples were acquired using a Shimadzu DTG-60H (Shimadzu Corp., Japan) with a simultaneous DTA-TG analyser. During the analysis, $30 \mathrm{mg}$ of sample was heated up to $450{ }^{\circ} \mathrm{C}$ in nitrogen stream, with heating rate of $20^{\circ} \mathrm{C} / \mathrm{min}$ [13].

Furthermore, XRD was used to analyse the crystal phase of the samples in which it was performed using D/MAX rA (Rigaku Co., Japan). The data were collected between $10^{\circ}$ to $70^{\circ}$ with a step size of $0.02^{\circ}[14]$.

\subsection{Hydrogen Temperature-Programmed Reduction $\left(\mathrm{H}_{2}\right.$-TPR) Experiment}

$\mathrm{H}_{2}$-TPR was performed using Thermo Finnigan TPDRO 1100 (Thermo Scientific, USA). Prior to the experiment, $20 \mathrm{mg}$ of samples was placed in a quartz tube reactor and pretreated under nitrogen gas flow of $30 \mathrm{ml} / \mathrm{min}$ at $150{ }^{\circ} \mathrm{C}$ for $10 \mathrm{~min}$ and cooled to ambient temperature. Then, $5 \% \mathrm{H}_{2} / \mathrm{Ar}$ gas flow at $25 \mathrm{ml} / \mathrm{min}$ was introduced to the samples to determine the hydrogen consumption (using thermal conductivity detector) from 50 to $950{ }^{\circ} \mathrm{C}$ with a ramp of $10{ }^{\circ} \mathrm{C} / \mathrm{min}$.

\section{Results and Discussion}

\subsection{FTIR characterization of catalysts}

The FTIR spectra of PKS, CS and the derivative catalysts are shown in Figure 1 and 2 respectively. It could be seen that there were certain changes in the surface functional groups due to impregnation of bimetals catalysts. Figure 1 displays the removal of peaks at $1743 \mathrm{~cm}^{-1}$ which shows the presence of carbonyl $(\mathrm{C}=\mathrm{O})$ group, referring to esters compound. In addition, the absorption of $\mathrm{sp}^{3}$ $\mathrm{C}-\mathrm{H}$ at $2952 \mathrm{~cm}^{-1}$ and broad peak at $1115 \mathrm{~cm}^{-1}$ due to stretching of C-O functional group referring to prominent ester for $\mathrm{Cu}-\mathrm{Mn} / \mathrm{PKS}$ was lower compared to PKS. This indicates that oxygenated groups were used by the metal oxides [13]-[15]. Furthermore, calcination process and nitrate decomposition might partly contribute to the structure change of AC [15].

Likewise, a single peak at $2406 \mathrm{~cm}^{-1}$, attributed to -OH functional group, which is carboxylic acids was seen to diminish in $\mathrm{Cu}-\mathrm{Mn} / \mathrm{CS}$, and at $3395 \mathrm{~cm}^{-1}$ attributed to -OH group was less compared to CS. Furthermore, new absorption peaks were observed for $\mathrm{Cu}-\mathrm{Mn} / \mathrm{CS}$ at $1419 \mathrm{~cm}^{-1}$ that corresponds to the COO- functional groups and at $1739 \mathrm{~cm}^{-1}$ that is contributed by the presence of $(\mathrm{C}=\mathrm{O})$ functional groups. This indicates that the acidic property of PKS has been enhanced by the dispersion of catalyst which is beneficial for $\mathrm{NH}_{3}$ adsorption during SCR reaction. 


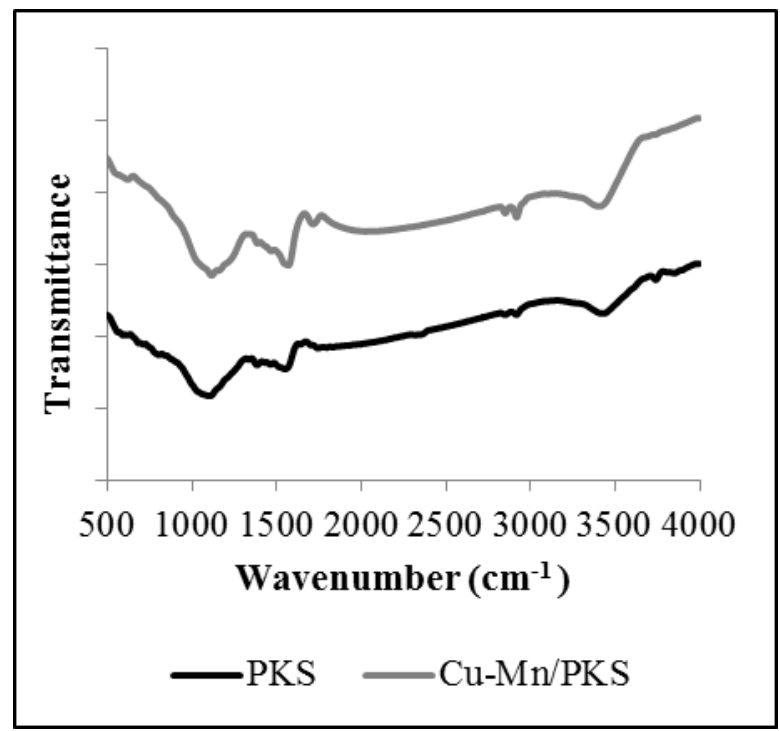

Figure 1. FTIR spectra of the PKS and Cu-Mn/PKS.

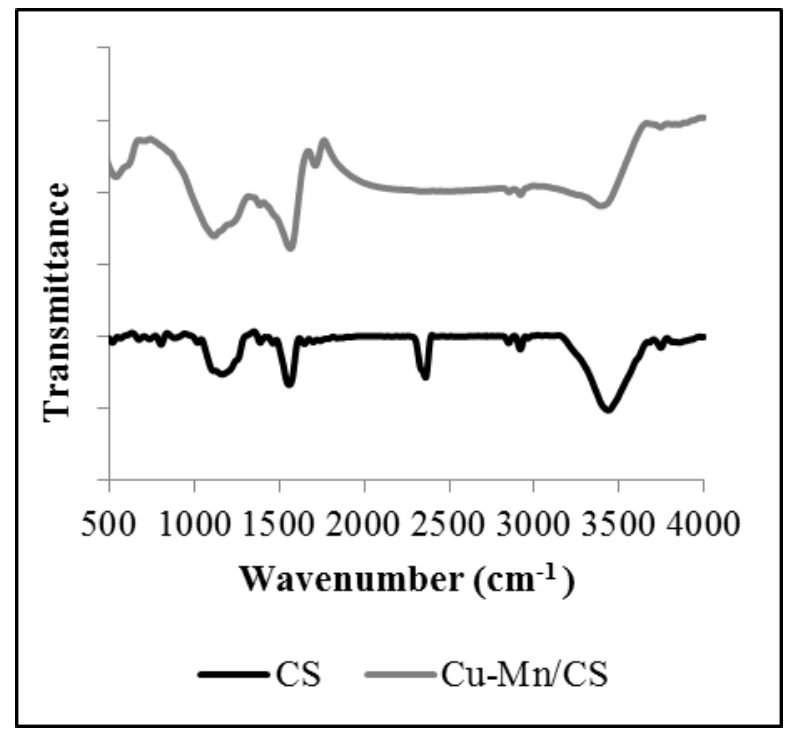

Figure 2. FTIR spectra of the CS and Cu-Mn/CS.

\subsection{TGA characterization of catalysts}

Figure 3 and 4 show the TGA curves of PKS, CS and the SCR catalysts synthesized from the two. The TGA curve for PKS in Figure 3(a) has a noticeable mass reduction peak around $55^{\circ} \mathrm{C}$ with about $6 \%$ mass reduced. Meanwhile in $\mathrm{Cu}-\mathrm{Mn} / \mathrm{PKS}$ as shown in Figure 3(b), the mass loss due to water shifted to a higher temperature range at around $110{ }^{\circ} \mathrm{C}$ where the reduced mass ranges from $2 \%$ to $8 \%$. In addition, the decomposition of organic matters occurred at around $180{ }^{\circ} \mathrm{C}$ to $400{ }^{\circ} \mathrm{C}$, and a sudden reduction of mass occurred at $361{ }^{\circ} \mathrm{C}$ to $450{ }^{\circ} \mathrm{C}$ indicating that the manganese have not yet fully decomposed [16].

In Figure 4(a), mass reduction of about $1 \%$ to $3 \%$ occurred in CS sample at around $55{ }^{\circ} \mathrm{C}$ and $110{ }^{\circ} \mathrm{C}$. Moreover, no peaks were observed in DTG curve at temperature $150{ }^{\circ} \mathrm{C}$ onwards. However, in Figure 4(b), two distinct weight loss regions were observed in $\mathrm{Cu}-\mathrm{Mn} / \mathrm{CS}$. The first region occurred between $25{ }^{\circ} \mathrm{C}$ to $110{ }^{\circ} \mathrm{C}$, followed by $110{ }^{\circ} \mathrm{C}$ onwards. A relative weight losses of $8 \%$ to $13 \%$ were 
observed at the first regions, corresponding to a loss of water. In the second region, a large weight loss of $17 \%$ was observed due to the decomposition of nitrates via equation (1) [17].

$$
2 \mathrm{Cu}\left(\mathrm{NO}_{3}\right)_{2} \rightarrow 2 \mathrm{CuO}_{2}+4 \mathrm{NO}_{2}+\mathrm{O}_{2}
$$

Both activated carbons are able to act as catalysts when surface modification is done and have the ability to withstand high temperature and it is suitable to be used in SCR system. However, for $\mathrm{Cu}-$ $\mathrm{Mn} / \mathrm{PKS}$ catalyst, the thermal stability might occur late as sudden reduction in mass occurs at the end of the analysis.

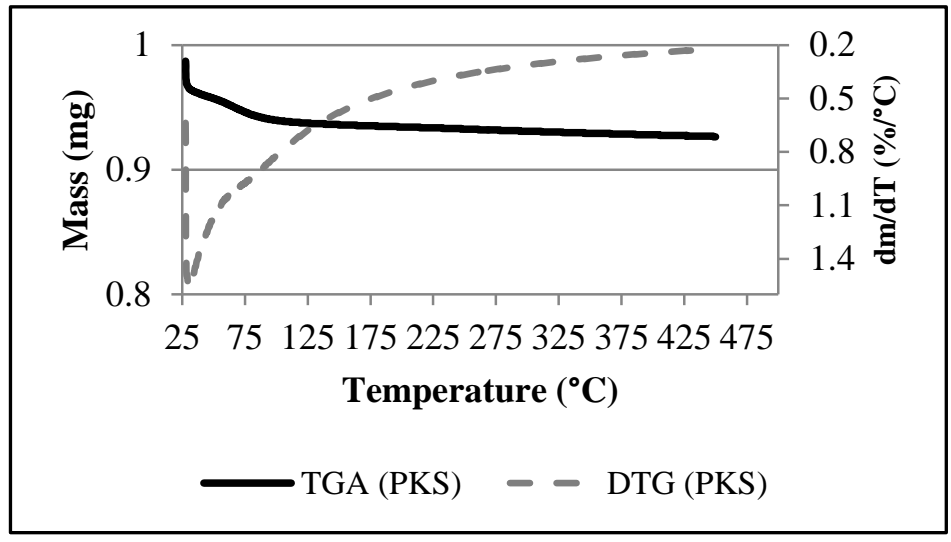

(a)

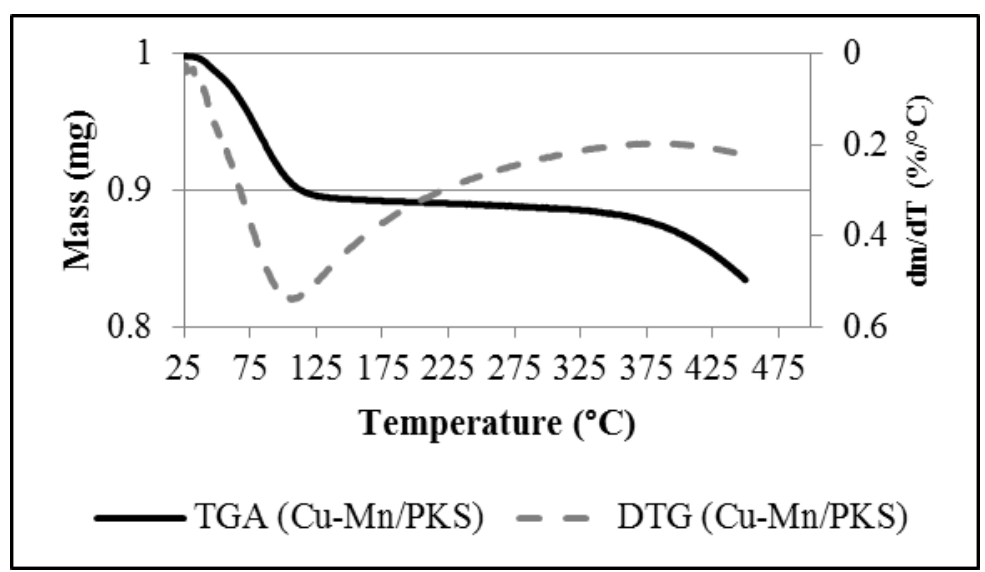

(b)

Figure 3. TGA-DTG curves of (a) PKS (b) Cu-Mn/PKS. 


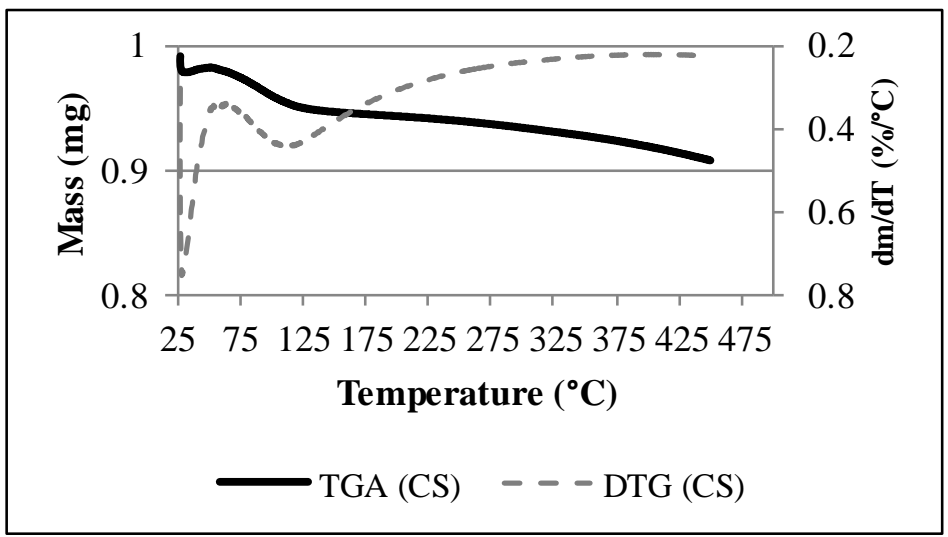

(a)

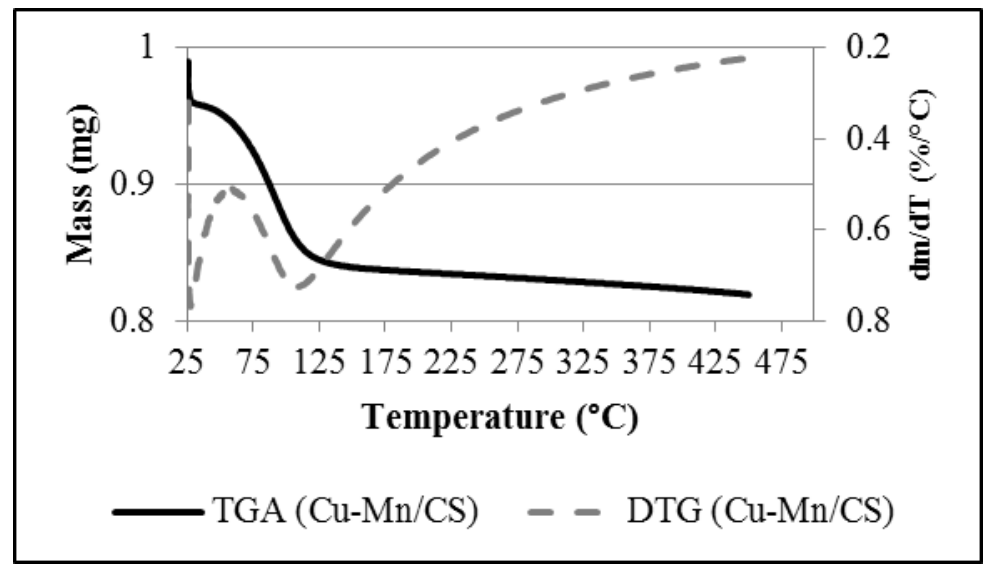

(b)

Figure 4. TGA-DTG curves of (a) CS (b) Cu-Mn/CS.

\subsection{XRD characterization of catalysts}

The x-ray diffraction patterns of SCR catalysts derived from PKS and CS are shown in Figure 5. A flat peak of $\mathrm{CuO}$ was observed at $2 \Theta=32^{\circ}$ and sharp peaks at $2 \Theta=35^{\circ}$ and $38^{\circ}$ referring to $\mathrm{Cu}_{2} \mathrm{O}$ [18]-[19]. The presence of $\mathrm{CuO}$ was expected due to the presence of divalent ions in the precursor salt [20]. The reduction processes of $\mathrm{CuO}$ can occur on activated carbons that are depicted in equations (2) and (3):

$$
\begin{aligned}
& 4 \mathrm{CuO}+\mathrm{C} \rightarrow 2 \mathrm{Cu}_{2} \mathrm{O}+\mathrm{CO}_{2} \\
& 2 \mathrm{Cu}_{2} \mathrm{O}+\mathrm{C} \rightarrow 4 \mathrm{Cu}+\mathrm{CO}_{2}
\end{aligned}
$$

In addition, a broad peak was observed at $25^{\circ}$ indicating the presence of $\mathrm{MnO}_{2}$, and it has high dispersion on the surfaces of PKS-derived catalysts. Higher peaks representing $\mathrm{MnO}_{2}$ crystalline planes were observed compared to a study by [21]. Furthermore, only sharp dispersion peaks of $\mathrm{MnO}$ were observed at $36^{\circ}$ in $\mathrm{Cu}-\mathrm{Mn} / \mathrm{CS}$, indicating the presence of $\mathrm{MnO}_{2}$ [22]-[23].

Dispersion of metal oxides on the surface of the catalysts is an important parameter that relates to the reactivity of the catalysts. Based on Figure 5, weak dispersion peaks were observed on the PKS- 
derived catalyst compared to CS-derived catalyst, which indicates that the metal oxides are highly dispersed, thus PKS is favorable for SCR [22]-[23].

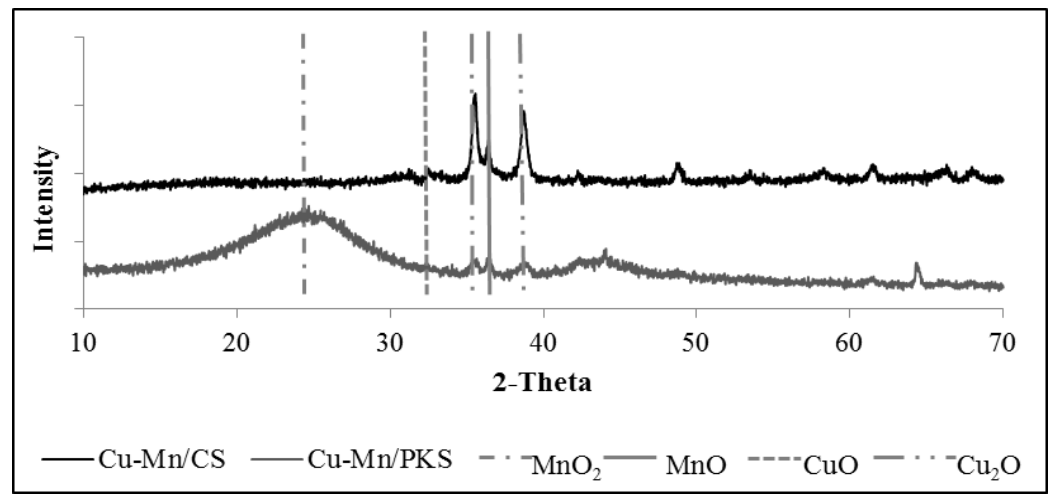

Figure 5: XRD patterns of $\mathrm{Cu}-\mathrm{Mn} / \mathrm{PKS}$ and $\mathrm{Cu}-\mathrm{Mn} / \mathrm{CS}$

\section{4. $\mathrm{H}_{2}$-TPR Experiment}

$\mathrm{H}_{2}$-TPR experiments were carried out with both $\mathrm{Cu}-\mathrm{Mn} / \mathrm{PKS}$ and $\mathrm{Cu}-\mathrm{Mn} / \mathrm{CS}$, and the results are shown in Figure 6 and Figure 7 respectively.

Hydrogen Temperature-Programmed Reduction $\left(\mathrm{H}_{2}\right.$-TPR) was used to determine the most efficient reduction temperature for the impregnated catalyst, as the oxidized catalyst is submitted to a programmed temperature rise while a reducing gas mixture is flowed over it.

The reduction peak at temperature range between $250{ }^{\circ} \mathrm{C}$ to $275^{\circ} \mathrm{C}$ is usually assigned to the reduction of $\mathrm{Cu}^{+2}$ ions to $\mathrm{Cu}^{+1}$ ions and reduction of $\mathrm{CuO}$ clusters while the high-temperature peak at $275{ }^{\circ} \mathrm{C}$ to $300{ }^{\circ} \mathrm{C}$ indicating that the oxide starts to reduce from $\mathrm{Cu}^{+1}$ ions to $\mathrm{Cu}$ ions. Furthermore, the reduction of $\mathrm{CuO}$ may occur directly as in equation (4) or sequential reduction as in equations (5a) and (5b) [24]-[25]:

$$
\begin{gathered}
\mathrm{CuO}+\mathrm{H}_{2} \rightarrow \mathrm{Cu}+\mathrm{H}_{2} \mathrm{O} \\
2 \mathrm{CuO}+\mathrm{H}_{2} \rightarrow \mathrm{Cu}_{2} \mathrm{O}+\mathrm{H}_{2} \mathrm{O} \\
\mathrm{Cu}_{2} \mathrm{O}+\mathrm{H}_{2} \rightarrow \mathrm{Cu}+\mathrm{H}_{2} \mathrm{O}
\end{gathered}
$$




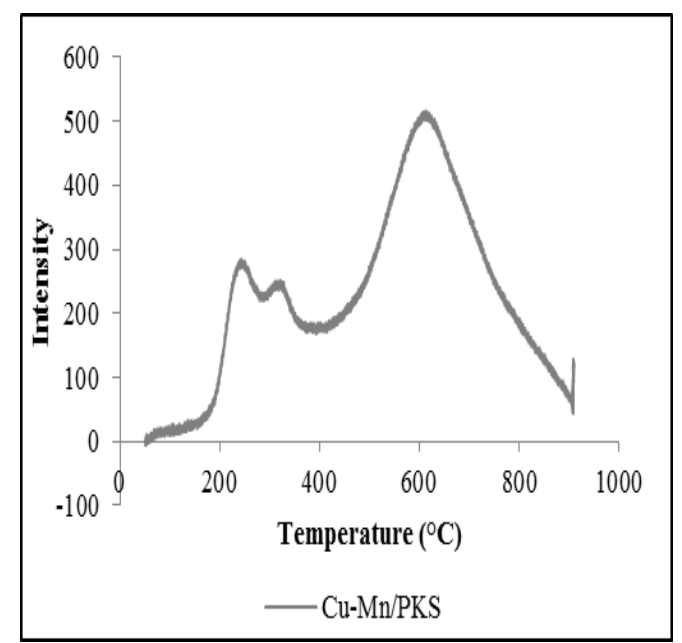

Figure 6: $\mathrm{H}_{2}$-TPR profiles of $\mathrm{Cu}-\mathrm{Mn} / \mathrm{PKS}$

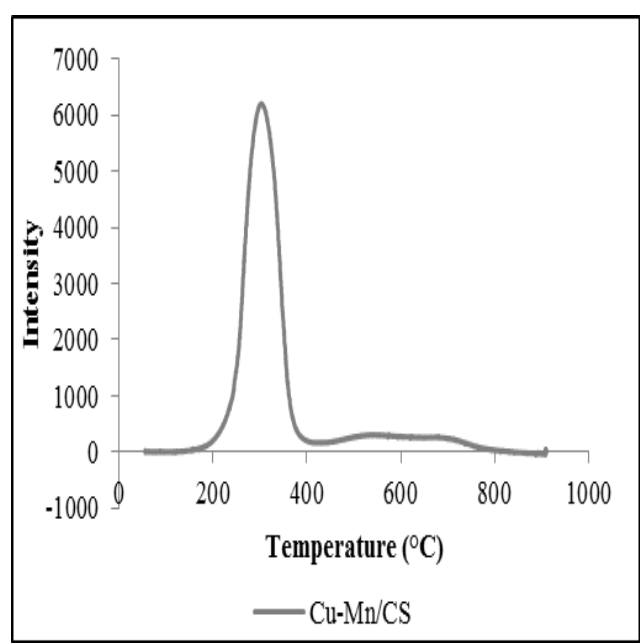

Figure 7: $\mathrm{H}_{2}$-TPR profiles of $\mathrm{Cu}-\mathrm{Mn} / \mathrm{CS}$

In $\mathrm{Cu}-\mathrm{Mn} / \mathrm{CS}$, only one reduction peak was observed at $294{ }^{\circ} \mathrm{C}$ as shown in Figure 7 where the reduction of $\mathrm{CuO}$ may occur as in (5a) as the XRD pattern showed the presence of both oxides. For $\mathrm{Cu}-\mathrm{Mn} / \mathrm{PKS}$ as shown in Figure 6, two small reduction peaks at $228{ }^{\circ} \mathrm{C}$ and $300{ }^{\circ} \mathrm{C}$ and one reduction peak at $597{ }^{\circ} \mathrm{C}$ can be observed. The reduction peak at $228{ }^{\circ} \mathrm{C}$ was contributed by the reduction of copper nitrate to copper oxide. The subsequent peaks are associated to the reduction of manganese via $\mathrm{MnO}_{2} \rightarrow \mathrm{Mn}_{3} \mathrm{O}_{4} \rightarrow \mathrm{MnO}$ [16]-[26]. The presence or absence of $\mathrm{Mn}_{3} \mathrm{O}_{4}$ cannot be ascertained from $\mathrm{XRD}$ analysis as these metals may be in ionic form and its substitutes into the carbon or copper [27].

The activities of the catalysts are expected to be enhance when the AC was impregnated with bimetals. The shifting of the metals reduction peaks to higher temperature demonstrates the intensity of the precursor/support interaction exists and a higher dispersion of bimetals on the surface of the support [28]. Based on XRD analysis, higher dispersion of bimetals on the surface was observed and the support interaction increased in the following order based on XRD and $\mathrm{H}_{2}-\mathrm{TPR}$ analysis: $\mathrm{Cu}-$ $\mathrm{Mn} / \mathrm{CS}<\mathrm{Cu}-\mathrm{Mn} / \mathrm{PKS}$. This analysis proves that high dispersion of metals on the surface of the catalyst boosting their activities. 


\section{Conclusion}

The catalytic activity of the activated carbon could be greatly improved by impregnation of bimetals copper and manganese. From the FTIR analysis, the distribution of oxygen functional groups increased after bimetals were impregnated onto the AC. Furthermore, in XRD analysis, weak dispersion of metal oxides was observed on the surface of PKS, which proved that the metal oxides are highly dispersed on this support. In addition, in $\mathrm{H}_{2}$-TPR analysis, the metals reduction peaks impregnated on PKS are at higher temperature compared to peaks in CS. This is due to strong interaction between the catalyst support and metal oxides. This result is in an agreement with XRD analysis. In conclusion, both biomass-porous carbons have the potential to be applied in SCR system. It was proven that impregnating bimetals onto activated carbon was able to boost the catalysts characteristics especially in PKS-derived catalysts. Hence, bimetallic impregnated catalysts based on PKS carbon support could be a new and promising catalyst.

However, it is also noted that further detailed analysis of the matter present within the activated carbon (with or without metals catalysts) should be done. Therefore, the author suggest that all analysis especially FTIR, TGA and XRD analysis must be done on both samples which is raw activated carbon and bimetals catalysts. Besides that, surface area, pore diameter and pore volume of raw activated carbon and catalysts must be conducted for next study so that the effect of impregnating bimetallic catalysts onto the carbon-support can be observed.

\section{Acknowledgement}

The authors wish to acknowledge Universiti Malaysia Sarawak for supporting this work under the RAGS/TK/05(1)/940/2012(41) grant and Universiti Putra Malaysia for the analysis works.

\section{References}

[1] West Central Airshed Society (2000). Annual Report. Canada. Retrieved October 18, 2013, from http://www.wcas.ca/documents/WCAS_AR_2000.pdf

[2] Bueno-Lopez, A. and Garcia-Garcia, A. (2004). Potassium-containing coal-pellets for $\mathrm{NO}_{\mathrm{x}}$ reduction, Carbon, Vol. 42, 1565-1574.

[3] Sounak,R., Hegde, M. S. and Madras, G. (2009). Catalysis for $\mathrm{NO}_{\mathrm{x}}$ abatement, Applied Energy, Vol. 86, 2283-2297.

[4] Yoshikawa, M., Yasutake, A. and Mochida, I. (1998). Low-temperature selective catalytic reduction of NOx by metal oxides supported on active carbon fibers, Applied Catalysis A: General, Vol. 173, 239245.

[5] Muniz, J., Marban, G. and Fuertes, A. B. (2000). Low-temperature selective catalytic reduction of NO over polyarylamide-based carbon fibres, Applied Catalysis B: Environmental, Vol. 23, 25-35.

[6] Jo, Y. B., Cha, J. S., Jeong, H. K., Shin, M. C., Park, S. H., Jeon, J. K., Kim, S. S. and Park, Y. K. (2011). $\mathrm{NH}_{3}$ Selective Catalytic Reduction (SCR) of nitrogen oxides over activated sewage sludge char, Korean Journal Chemical Engineering, Vol. 28, No. 1, 106-113.

[7] Garcia-Cortes, J. M., Perez-Ramirez, J., Illan-Gomez, M. J., Kapteijin, F., Moulijin, J. A. and SalinasMartines de Lecea, C. (2000). Comparative study of Pt-based catalysts on different supports in the lowtemperature de- $\mathrm{NO}_{\mathrm{x}}$-SCR with propene, Applied Catalysis B: Environmental, Vol. 30, 399-408.

[8] Olowoyo, D. N. and Orere, E. E. (2012). Preparation and characterization of activated carbon made from palm-kernel shell, coconut shell, groundnut shell and obeche wood (Investigation of apparent density, total ash content, moisture content, particle size distribution parameters), International Journal of Research in Chemistry and Environment, Vol. 2, No. 3, 32-35.

[9] Leimkuehler, E. P (2010). Production, characterization, and applications of activated carbon, Master of Science, University of Missouri, United States. 
[10] Cha, J. S., Choi, J. C., Ko, J. H., Park, Y. K., Park, S. H., Jeong, K. E., Kim, S. S. and Jeon, J. K. (2010). The low temperature SCR of NO over rice straw and sewage sludge derived char, Chemical Engineering Journal, Vol. 156, 321-327.

[11] Baseri, J. R., Palanisamy, P. N. and Sivakumar, P. (2012). Preparation and characterization of activated carbon from Thevetia peruviana for the removal of dyes from textile wastewater, Advances in Applied Science Research, Vol. 3, No. 1, 377-383.

[12] Wang, C., Zuo, Y. and Yang, C. L. (2009). Selective catalytic reduction of $\mathrm{NO}$ by $\mathrm{NH}_{3}$ in flue gases over a $\mathrm{Cu}-\mathrm{V} / \mathrm{Al}_{2} \mathrm{O}_{3}$ catalysts at low temperature, Environmetal Engineering Science, Vol. 25, No. 9, 1429-1434.

[13] Lu, P., Li, C., Zeng, G., He, L., Peng, D., Cui, H., Li, S. and Zhao, Y. (2010). Low temperature selective catalytic reduction of NO by activated carbon fiber loading lanthanum oxide and ceria, Applied Catalysis B: Environmental, Vol. 96, 157-161.

[14] Chen, X., Gao, S., Wang, H., Liu, Y. and Wu, Z. (2011). Selective catalytic reduction of NO over carbon nanotubes supported $\mathrm{CeO}_{2}$, Catalysis Communications, Vol. 14, 1-5.

[15] Huang, B., Huang, R., Jin, D. and Ye, D. (2007). Low temperature SCR of NO with $\mathrm{NH}_{3}$ over carbon nanotubes supported vanadium oxides, Catalysis Today, Vol. 126, 279-283.

[16] Kapteijin, F., Singoredjo, L. and Andreini, A. (1994). Activity and selectivity of pure manganese oxides in the selective catalytic reduction of nitric oxide with ammonia, Applied Catalysis B: Environmental, Vol. 3, 173-189.

[17] Alouche, A. (2008). Preparation and characterization of copper an/or cerium catalysts supported on alumina or ceria, Jordan Journal of Mechanical and Industrial Engineering, Vol. 2, No. 2, 111-116.

[18] Ryu, S. K., Lee, W. K., Park, S. J. and Edie, D. D. (2004). Nitric oxide (NO) removal on copper impregnated activated carbon fibers, Department of Chemical Engineering, Chungnam University, Korea.

[19] El-Molla, S., El-Shobaky, G. A., Amin, N. H., Hammed, M. N. and Sultan, S. N. (2013). Catalytic properties of pure and $\mathrm{K}^{+}$-doped $\mathrm{CuO} / \mathrm{MgO}$ system towards 2-propanol conversion, Journal of the Mexican Chemical Society, Vol. 57, No. 1, 36-42.

[20] Martinez, N. D., Venturini, R. B., Silva, H. S., Gonzalez, J. E. and Rodriguez, A. M. (2009). Copper on activated carbon for catalytic wet air oxidation, Materials Research, Vol. 12, No. 1, 45-50.

[21] Singh, S., Nahil, M. A., Sun, X., Wu, C., Chen, J., Shen, B. and Williams, P. T. (2012). Novel application of cotton stalks as a waste derived catalyst in the low temperature SCR-deNO $\mathrm{x}_{\mathrm{x}}$ process, Fuel.

[22] Pourkhalil, M., Rashidi, A. M. and Moghaddam, A. Z. (2012). Preparation of nanocatalyst supported on carbon nanotubes for low-temperature selective catalytic reduction of $\mathrm{NO}_{\mathrm{x}}$, Proceedings of the $4^{\text {th }}$ International Conference on Nanostructures (ICNS4), 1008-1010.

[23] Athappan, A. (2012). Selective catalytic reduction of nitric oxide over cerium-doped activated carbons, Doctor of Philosophy, University of Texas at Arlington, United States.

[24] Kim, J. Y., Rodriguez, J. A., Hanson, J. C., Frenkel, A. I., and Lee, P. L. (2003). Reduction of CuO and $\mathrm{Cu}_{2} \mathrm{O}$ with $\mathrm{H}_{2}$ : $\mathrm{H}$ embedding and kinetic effects in the formation of suboxides, Journal of the American Chemical Society, Vol. 125, No. 35, 10684-10692.

[25] Kundakovic, Lj., and Flytzani-Stephanopoulos, M. (1998). Reduction characteristics of copper oxide in cerium and zirconium oxide systems, Applied catalysis A: General, Vol. 171, 13-29.

[26] Ostrovski, O., Anacleto, N., and Ganguly, S. (2004). Reduction of manganese ores by methane containing gas, Proceedings Tenth International Ferroalloys Congress, 173-183.

[27] Sharma, S., Chaudhary, S., Kashyap, S. C. and Malik, V. K. (2011). DC magnetization investigations in $\mathrm{Ti}_{1-\mathrm{x}} \mathrm{Mn}_{\mathrm{x}} \mathrm{O}_{2}$ nanocrystalline powder, Journal of Alloys and Compounds, Vol. 509, No. 27, 7434-7438.

[28] Oliveira, H. A., Franceschini, D. F., and Passos, B. F. (2012). Support effect on carbon nanotube growth by methane chemical vapor decomposition on cobalt analysis, Journal of Brazilian Chemical Society, Vol. 23, No. 5, 868-879. 


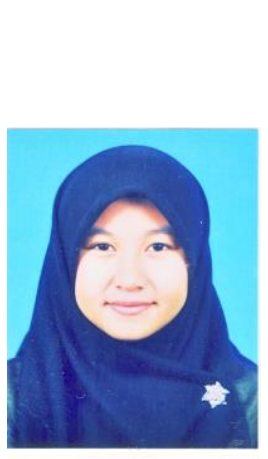

\begin{abstract}
Authors

\section{Arfaezah Anuar}

Arfaezah Anuar was a student in the Department of Chemical Engineering \& Energy Sustainability, Faculty of Engineering, Universiti Malaysia Sarawak (UNIMAS). She has developed an interest in material characterization, adsorption and catalysis for environmental and energy applications.
\end{abstract}

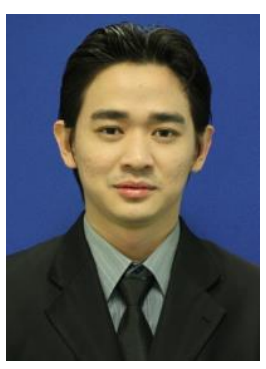

\title{
Ibrahim Yakub
}

Ibrahim Yakub is a lecturer in the Department of Chemical Engineering \& Energy Sustainability, Faculty of Engineering, Universiti Malaysia Sarawak (UNIMAS). He obtained his Masters in Engineering (Chemical Process) from Universiti Kebangsaan Malaysia (UKM). His research interest is catalyst development from biomass for energy and environmental applications.

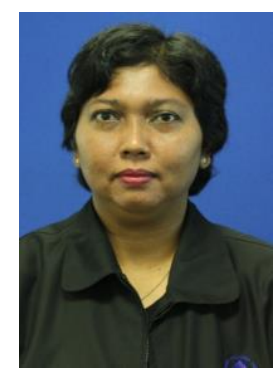

\section{Norsuzailina Mohamed Sutan}

Norsuzailina Mohamed Sutan is a senior lecturer in the Department of Civil Engineering, Faculty of Engineering, Universiti Malaysia Sarawak (UNIMAS). She obtained her PhD from UNIMAS and her research interest is material characterisation and pozzolanic reaction.

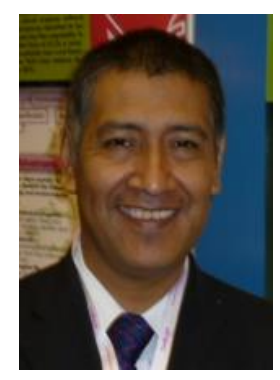

\section{Cirilo Nolasco Hipolito}

Cirilo Nolasco Hipolito is a senior lecturer in the Department of Molecular Biology, Faculty of Research Science \& Technology, Universiti Malaysia Sarawak (UNIMAS). He obtained his PhD from Kyushu University, Japan and his area of specialization is Microbial Technology. He is also an expert on Ethanol Technology in a continuous culture for the project "Pilot Scale High Speed Fermentation of Ethanol for Fuel from Sago Utilizing the Ishizaki Process".

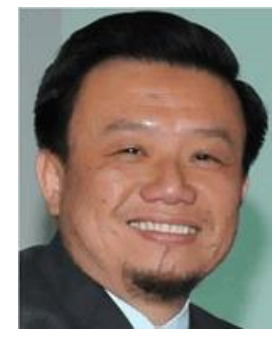

\section{Yun Hin Taufiq-Yap}

Yun Hin Taufiq-Yap is the Director at the Catalysis Science and Technology Research Centre, Faculty of Science, Universiti Putra Malaysia (UPM). He is also a senior lecturer in the Department of Chemistry, Faculty Science, UPM. $\mathrm{He}$ obtained his $\mathrm{PhD}$ from University of Manchester Institute of Science and Technology, U. K. His research interests include heterogenous catalysis and green energy production. 